\title{
Phenolic compounds and antioxidants extraction using pressurized liquids and ultrasound, mineral potential and bioacessibility in yellow passion fruit rind (Passiflora edulis flavicarpa)
}

\section{Camila Messina*, Ana P. Rebellato, Juliana A. L. Pallone, Juliane Viganó, Julian Martínez}

\begin{abstract}
Considering the vast amount of food waste along the agroindustrial chain, the recovery of the residues and its processing seems to be a great oportunity for the development of by-products. Furthermore, it allows adding the lost value of that part of the production process to the residue and even giving it a sustainable reuse ${ }^{1}$. The main purpose of this research was to analyze the residues of passion fruit processing and determine which compounds are found in it and, most of all, which of them are accessible and usable.
\end{abstract}

\section{Key words:}

passion fruit rind, Pressurized Liquid Extraction, minerals

\section{Introduction}

The aim of this study was to examine the different conditions of Pressurized Liquid Extraction (PLE) from yellow passion fruit (Passiflora edulis flavicarpa) rind. The attempt to add value to the agroindustrial waste of the fruit and the recovery of its bioactive compounds was the major motivation of the study, since those are of great interest to food and pharmaceutical industries. Moreover, the waste through the production chain is a significant socio-environmental and economic issue. The PLE extractions assisted by ultrasound (Unique Group, DES500, Campinas, Brazil) were performed at different powers: 140, 260, 400 e $560 \mathrm{~W}$. Extractions not assisted by ultrasound were also made. The extractions were performed in a unit assembled at the Laboratory of High Pressure in Food Engineering (LAPEA/DEA/FEA, Unicamp, Campinas, Brazil) at $60^{\circ} \mathrm{C}$ and $10 \mathrm{MPa}$.

The mineral potential and the bioacessibility of the passion fruit rinds, unextracted and subjected to PLE, were analyzed. Iron, calcium, manganese, potassium, sodium, magnesium, copper and zinc minerals were potentialized by Flame Atomic Absorption Spectroscopy (FAAS). The bioacessibility was evaluated by the solubility and the dialysis methods in the Laboratory of Food Analysis II (LAA-II/ DCA/ FEA, Unicamp, Campinas, Brazil).

\section{Results and Discussion}

The extraction condition that achieved the highest levels of phenolic and antioxidants compounds, which were, respectively, analyzed by the Folin-Ciocalteu and Iron Reduction methods, was the one assisted by ultrasound at $400 \mathrm{~W}$, followed by the one without ultrasound. Due to its high energy consumption and no statistical difference between the samples, PLE at $400 \mathrm{~W}$ appears as not economically viable.

A linear correlation between phenolic content and antioxidant capacity at different extraction conditions was found, as shown in Figure 1.

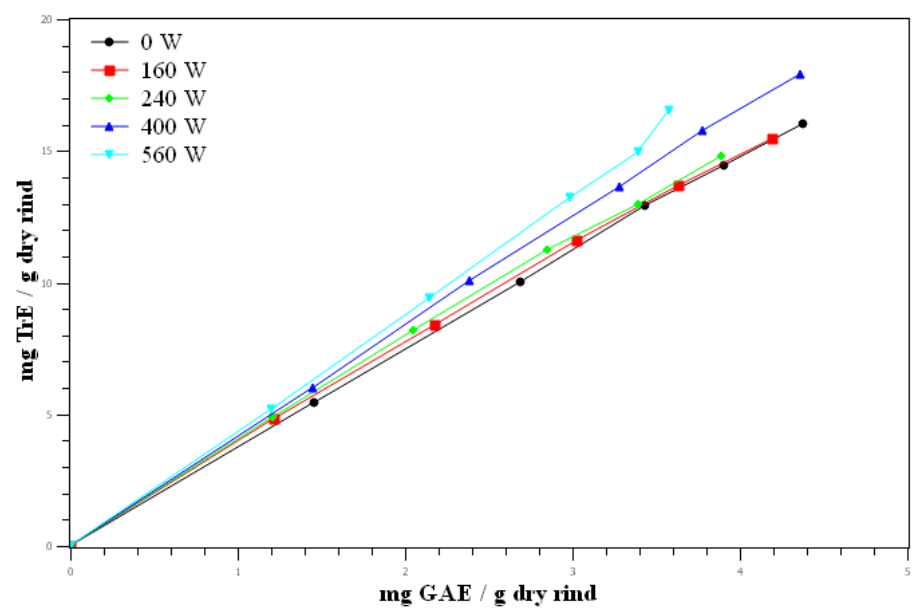

Image 1. Correlation between antioxidant capacity and phenolic content of PLE extracts from passion fruit rind.

The rind showed a high potassium concentration, followed by calcium, magnesium and sodium. The unextracted samples presented higher amounts of minerals when compared to those subjected to PLE, which however still contain significant amounts of these minerals.

The amount of dialyzed mineral was also measured. As in mineral potential, the percentage of bioacessibility in the unextracted sample was higher than in the rinds that underwent PLE.

\section{Conclusions}

Passion fruit rind is an interest source for functional compounds and minerals. As is contains considerable amounts of minerals after a sequence of extractions, this by-product may be a promising investment for technological productions.

\section{Acknowledgement}

The authors acknowledge PIBIC-CNPq for the scholarship and FAPESP (2017/23670-2) for the research grant.

1 COSTA FILHO, D. V.; SILVA, A. J.; SILVA, P. A. P.; SOUSA, F. C., Aproveitamento de resíduos agroindustriais na elaboração de subprodutos. Cointer -PDVAgro, 2017. 